\title{
OPTICAL GAS SENSITIVITY OF A METALOXIDE MULTILAYER SYSTEM WITH GOLD-NANO-CLUSTERS
}

\author{
A. Schleunitz ${ }^{1}$, H. Steffes ${ }^{2}$, R. Chabicovsky ${ }^{3,{ }^{*}, \text { K. Piglmayer }^{4} \text {, E. Obermeier }}{ }^{5}$ \\ ${ }^{1}$ BESSY GmbH, Application Center for Microengineering, D-12489 Berlin, Germany \\ ${ }^{2}$ Berlin University of Technology, Microsensor and Actuator Technology, D-13355 Berlin, Germany, \\ Current address: Robert Bosch GmbH, Automotive Electronics, D-72703 Reutlingen, Germany \\ ${ }^{3}$ Vienna University of Technology, Institute of Sensor and Actuator Systems, A-1040 Wien, Austria \\ ${ }^{4}$ University of Linz, Institute of Applied Physics, A-4040 Linz, Austria \\ ${ }^{5}$ Berlin University of Technology, Microsensor and Actuator Technology, D-13355 Berlin, Germany \\ *Corresponding author: Rupert Chabicovsky, Phone +43-1-58801-36651, Fax +43-1-58801-36699, \\ e-mail rupert.chabicovsky@tuwien.ac.at
}

\begin{abstract}
We report on the optical gas sensitivity of a sputtered multilayer system consisting of $\operatorname{In}_{\mathrm{x}} \mathrm{O}_{\mathrm{y}} \mathrm{N}_{\mathrm{z}}$ and gold-nano-clusters. This system shows a reversible change in the optical absorption (increase or decrease) during exposure to reducing or oxidizing gases in air. We demonstrate the optical gas sensitivity at a temperature of $400{ }^{\circ} \mathrm{C}$ with some exemplary gas samples: carbon monoxide, nitrogen dioxide and hydrogen in dry air.
\end{abstract}

Keywords: optical gas sensitivity, gold-nano-clusters, $\mathrm{Au} / \mathrm{In}_{\mathrm{x}} \mathrm{O}_{\mathrm{y}} \mathrm{N}_{\mathrm{z}}$ multilayer system

\section{INTRODUCTION}

Novel optochemical sensors are gaining more and more attention for the detection and determination of chemical and biological quantities due to their advantages over conventional chemical sensors. One type of optochemical sensors is based on a reversible change in absorption during the exposure to reducing or oxidizing gases. This sensing effect can be observed at several composites of metal oxides (e.g., $\mathrm{NiO}, \mathrm{Co}_{3} \mathrm{O}_{4}$, $\mathrm{Mn}_{3} \mathrm{O}_{4}, \mathrm{CuO}$ and $\mathrm{WO}_{3}$ ) and nano-scaled gold particles (gold-clusters) making these materials very suitable for optical gas sensors [1-4]. The absorption and scattering of light by small metal clusters is generally a subject of research activities $[5,6]$.

Apart from the optical gas sensitivity mentioned above the combination of gold clusters and metal oxides additionally shows a well-known electrical gas sensitivity (change of electrical conductivity at exposure to gases). Combining these two sensing effects could be used to improve the selectivity of gas measuring systems.

\section{TECHNOLOGY}

The metal oxide multilayer systems used in this work were sputter-deposited onto quartz substrates (18 mm x $18 \mathrm{~mm} \times 0.42 \mathrm{~mm}$ ) using an RFmagnetron sputtering system (Leybold-Heraeus Z660). A sintered $\ln _{2} \mathrm{O}_{3}$ target (diameter: $20 \mathrm{~cm}$, purity: $99.99 \%$ ), an RF-power of $100 \mathrm{~W}$ and a high purity $\mathrm{Ar} / \mathrm{N}_{2}$ process atmosphere (35\% Ar / $65 \%$ $\mathrm{N}_{2}$ at $9 \times 10^{-3}$ mbar) have been used for the production of the $\ln _{x} \mathrm{O}_{y} \mathrm{~N}_{z}$ films [7]. The ultra thin gold layers were deposited by DC-sputtering (200 $\mathrm{W}$, pure Ar atmosphere, substrate rotation mode). We have fabricated a stack of 10 double layers of $\operatorname{In}_{x} \mathrm{O}_{y} N_{z}$ and gold (Fig.1). The thickness of one double layer after deposition is $12 \mathrm{~nm}$ or $14 \mathrm{~nm}$ (10 $\mathrm{nm} \ln _{\mathrm{x}} \mathrm{O}_{\mathrm{y}} \mathrm{N}_{\mathrm{z}}, 2 \mathrm{~nm}$ or $4 \mathrm{~nm}$ gold).

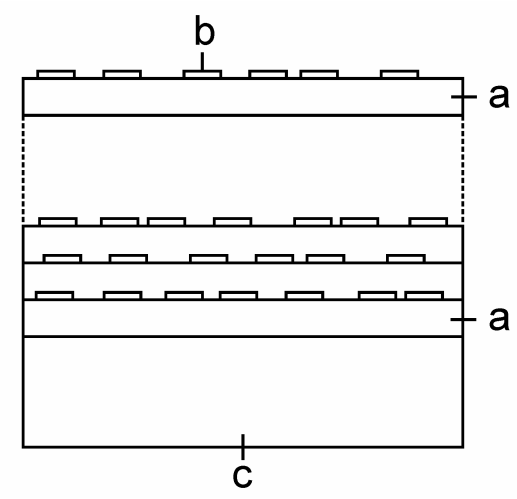

Figure 1. Schematics of the gas sensitive multilayer system: (a) 10 sputtered $\ln _{x} O_{y} N_{z}$ films, (b) randomly distributed gold-nano-cluster ensembles, (c) quartz substrate, dimensions $18 \mathrm{~mm} \times 18 \mathrm{~mm} \times 0.42 \mathrm{~mm}$.

The fabrication was completed after an annealing step at $600{ }^{\circ} \mathrm{C}$ for $8 \mathrm{~h}$ in synthetic air at a flow rate of $4 \mathrm{l} / \mathrm{min}$ in a quartz oven. The annealing leads to a nano-crystalline porous structure of the $\operatorname{In}_{x} \mathrm{O}_{y} N_{z}$ with a mean crystallite size of $27 \mathrm{~nm}$. The nanocrystalline structure is caused by the diffusion of nitrogen during annealing. Auger electron spectroscopy (AES) has proven, that about 1 at.\% 2 at.\% nitrogen is stored in the $\ln _{x} \mathrm{O}_{y} \mathrm{~N}_{z}$ films after annealing.

The gold-nano-clusters which accumulate during the annealing process by coagulation are incorporated in the volume and on the surface of the multilayer system. SEM analysis revealed a statistical distribution of the clusters on the surface (Fig.2). The gold-nano-clusters on the surface have diameters of $20-40 \mathrm{~nm}$ and $60-90 \mathrm{~nm}$ for multilayer systems with $2 \mathrm{~nm}$ and $4 \mathrm{~nm}$ sputtered gold, respectively [8]. BSE (back scattered electron) micrographs have been used to study the gold particles in the volume. We have seen that the size 
and shape of the gold particles in the volume depend strongly on the thickness of the sputtered gold layers. In the case of $4 \mathrm{~nm}$ gold we have found fibre-like gold particles compared to rather spheric particles in the samples with $2 \mathrm{~nm}$ gold [9]. The size of volume particles is significantly larger compared to surface particles.

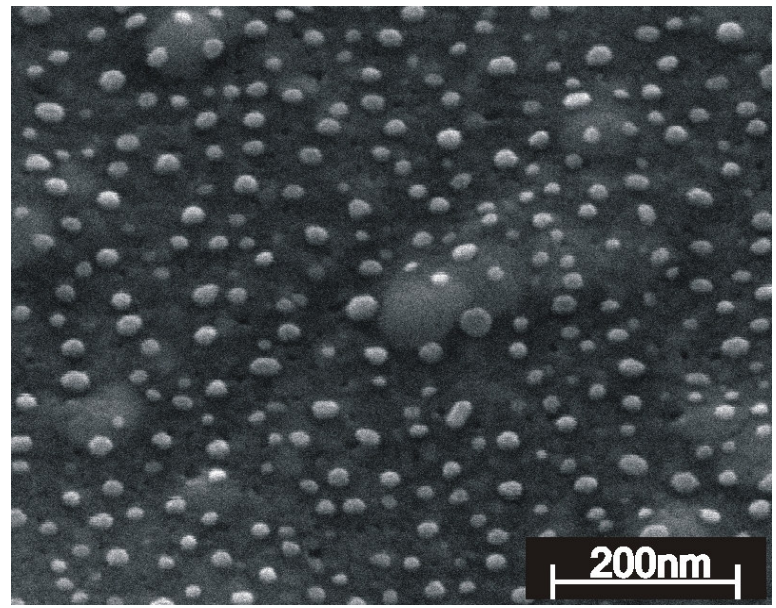

Figure 2. SEM micrograph of the $A u / I n_{x} O_{y} N_{z}$ multilayer surface after sample annealing at $600^{\circ} \mathrm{C} / 8 \mathrm{~h}$. The thickness of the gold-films before annealing is $2 \mathrm{~nm}$. Magnification: 150000 / $20 \mathrm{kV}$, incidence angle: 46 .

\section{MEASUREMENTS AND RESULTS}

Preliminary investigations of the optical gas sensitivity of the layer system have been performed using a special chamber equipped with a red light emitting diode (AlGaAs, $660 \mathrm{~nm} \pm 20 \mathrm{~nm}$ ), a cadmium sulfide photoresistor and a sample heater. This plain set-up shows that the sensing effect can be used in a very easy manner indicating the prospect of highly integrated sensor systems.

For a more detailed spectral investigation a somewhat modified set-up was used (Fig.3). The LED has been replaced by a self-made tunable light source consisting of a $100 \mathrm{~W}$ halogen lamp with a stabilized power supply and a prismmonochromator SPM2 (with LiF-82 Prism, Carl Zeiss Jena). The monochromatic light is coupled into a fiber optic and then guided into the measurement chamber where the incident light is partly absorbed by the multilayer system. The sample is heated up to a temperature of $400{ }^{\circ} \mathrm{C}$ by a transparent heater. During gas exposure the absorbance of the sample changes and thus the measured photoresistance of the light sensor. Reference measurements with pure quartz substrates (without a sensing film) revealed no changes in the optical transmission during exposure to reducing and oxidizing gases. Thus, absorption effects in the air/gas atmosphere can be neglected.

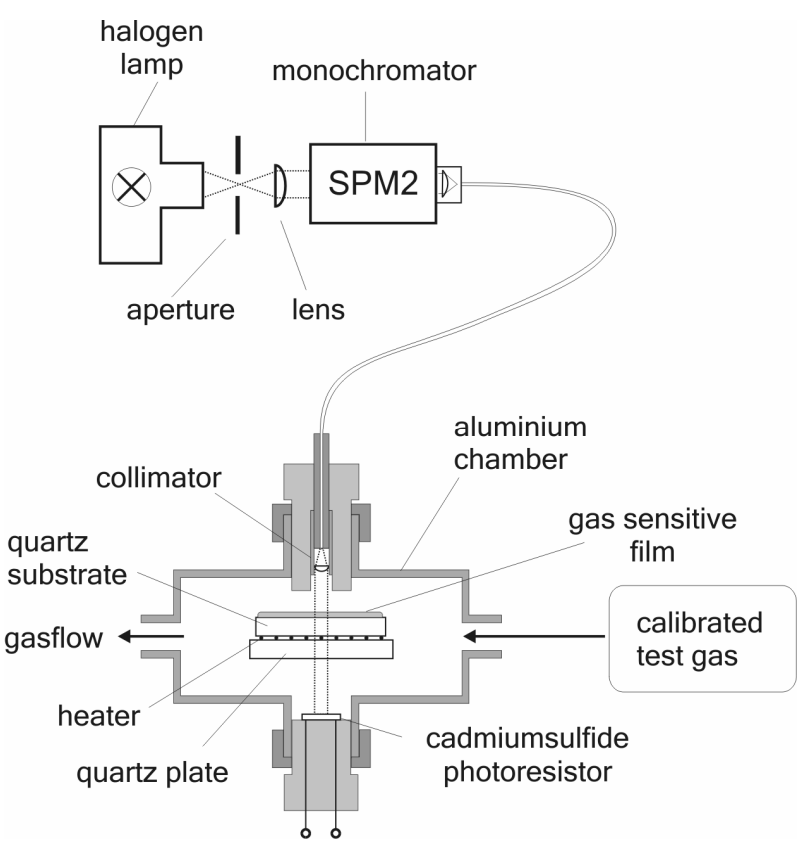

Figure 3. Schematic illustration of the measurement setup for spectral investigations. The quartz substrate with the gas sensitive layer is heated up to $400^{\circ} \mathrm{C}$. The sample is exposed to traces of gas accurately mixed in dry synthetic air. The transmission measurements were performed using a photoresistor and fiber optics coupled to a polychromatic light source.
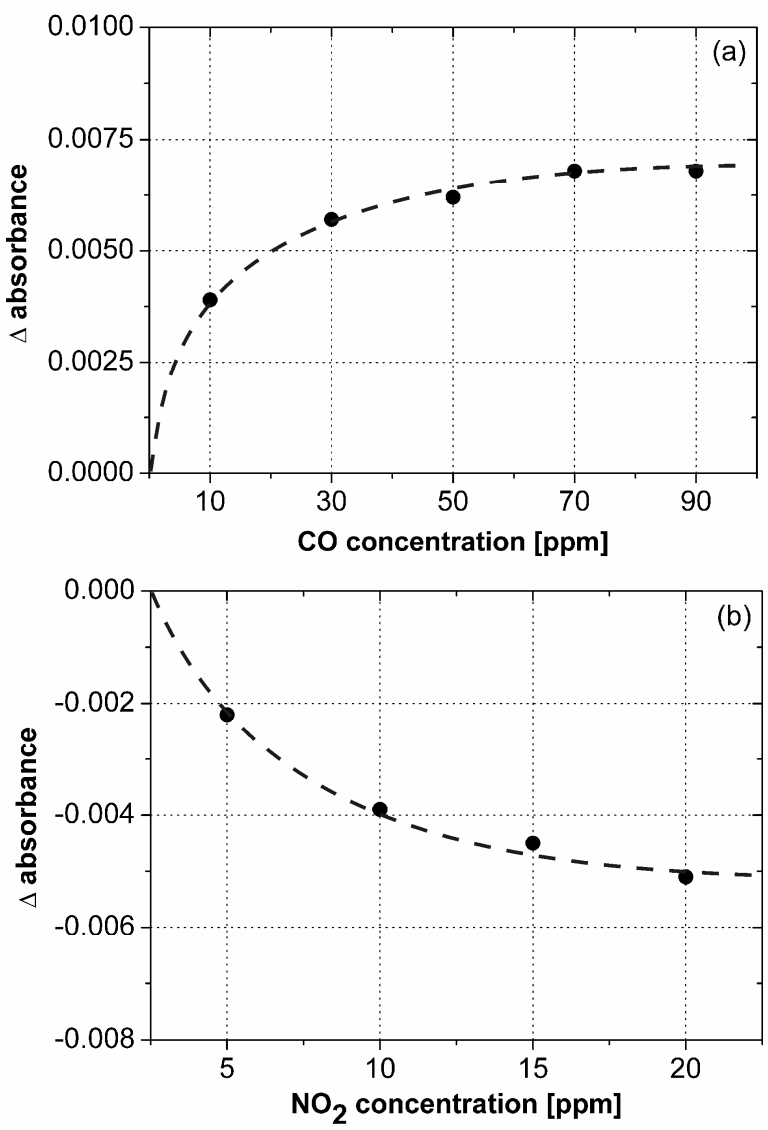

Figure 4. Change of absorbance of the $A u / I n_{x} O_{y} N_{z}$ multilayer system (with sputtered $2 \mathrm{~nm}$ gold-film and annealed at $600{ }^{\circ} \mathrm{C}$ for $8 \mathrm{~h}$ ) as a function of the gas concentration, measured at an operating temperature of $400{ }^{\circ} \mathrm{C}$. Measurements at $660 \mathrm{~nm}$ (LED). (a) Carbon monoxide in dry air, (b) Nitrogen dioxide in dry air. 
The absorbance is generally determined by

$$
A=\log \left(I_{0} / l\right)
$$

where $I_{o}$ is the light intensity observed for a naked quartz sample and I the intensity for a quartz sample with gas sensitive layer. Furthermore, the change of absorbance during the gas exposure can be calculated approximately by the formula

$$
\Delta A=\log \left(R_{\text {gas }} / R_{\text {air }}\right)
$$

where $R_{\text {gas }}$ is the resistance of the cadmium sulfid detector in the gas atmosphere and $R_{\text {air }}$ is the resistance of the detector in air.

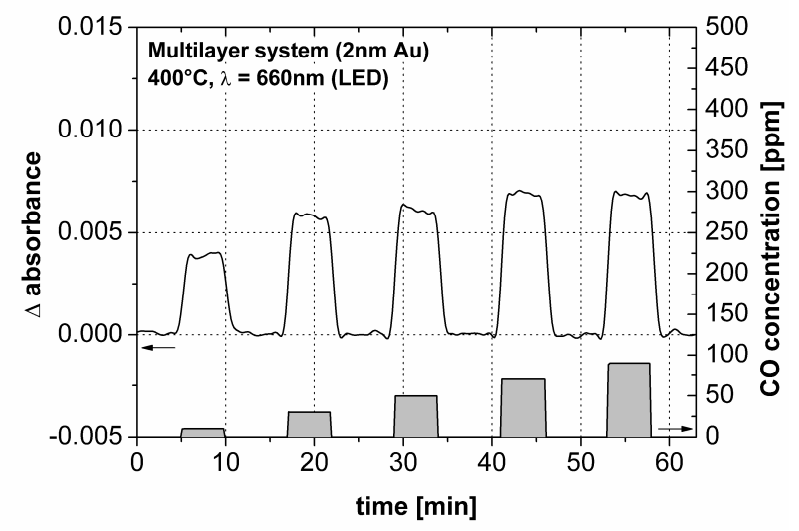

Figure 5. Transient absorbance change of the Au/ $\mathrm{In}_{x} \mathrm{O}_{y} \mathrm{~N}_{z}$ multilayer system (with sputtered $2 \mathrm{~nm}$ gold-films and annealed at $600^{\circ} \mathrm{C}$ for $8 \mathrm{~h}$ ) at exposure to carbon monoxide in dry air measured at an operating temperature of $400{ }^{\circ} \mathrm{C}$.

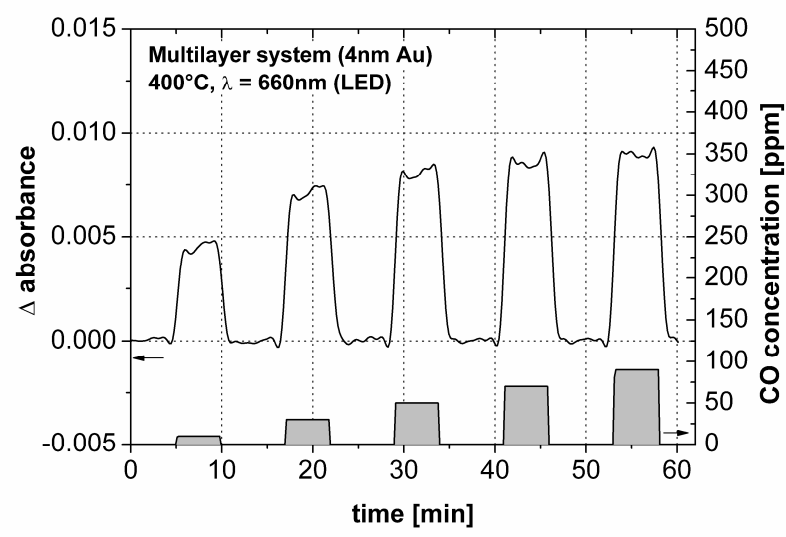

Figure 6. Transient absorbance change of the Au/ $\mathrm{In}_{x} \mathrm{O}_{y} \mathrm{~N}_{z}$ multilayer system (with sputtered $4 \mathrm{~nm}$ gold-films and annealed at $600{ }^{\circ} \mathrm{C}$ for $8 \mathrm{~h}$ ) at exposure to carbon monoxide in dry air measured at an operating temperature of $400^{\circ} \mathrm{C}$.

We have investigated the change of absorbance of the multilayer system at exposure to $10-90 \mathrm{ppm}$ of carbon monoxide (reducing gas) and to 5-20 ppm of nitrogen dioxide (oxidizing gas). Measurements carried out with the LED light source mentioned above are shown in Fig.4. If the multilayer system is exposed to carbon monoxide, we receive a positive change of absorbance (increase of absorbance). Nitrogen dioxide causes a negative change of absorbance (decrease of absorbance). This specific behaviour of the optical gas sensor is similar to that of the well known conventional metal oxide gas sensors where the electrical conductivity is changed (with different signs) at exposure to reducing or oxidizing gases.

The transient behaviour for carbon monoxide is shown in the Figs.5 and 6. This measurement was carried out with the LED light source equipment. A comparison of the two figures demonstrates the influence of the gold thickness. The sensing effect is stronger in the case of a sample with $4 \mathrm{~nm}$ gold film (particle size after annealing 60-90 nm) compared to a sample with $2 \mathrm{~nm}$ gold film (particle size after annealing 20-40 nm). In Fig.7 we present the transient behaviour for nitrogen dioxide. This measurement was carried out with the monochromator equipment and shows results achieved with two different wavelengths. The measuring effect is stronger at a wavelength of 600 $\mathrm{nm}$ compared to $660 \mathrm{~nm}$. In all cases the response time and recovery time is in the order of one minute (depending on the value of the concentration step).

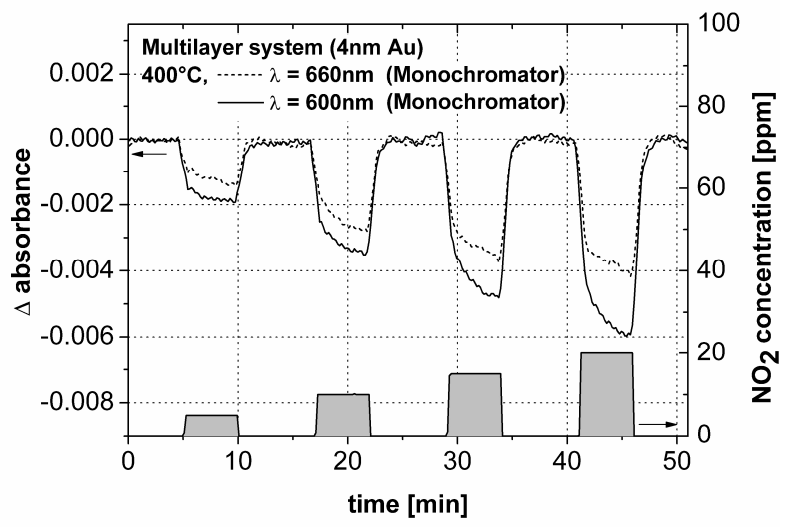

Figure 7. Transient absorbance change of the Au/ $\mathrm{In}_{x} \mathrm{O}_{y} \mathrm{~N}_{z}$ multilayer system (with sputtered $4 \mathrm{~nm}$ gold-films and annealed at $600^{\circ} \mathrm{C}$ for $8 \mathrm{~h}$ ) at exposure to nitrogen dioxide in dry air measured at an operating temperature of $400{ }^{\circ} \mathrm{C}$.

In Fig.8 we show absorbance spectra of multilayer systems in the wavelength range from $600 \mathrm{~nm}$ to $700 \mathrm{~nm}$ measured in dry air and under exposure to hydrogen (reducing gas causing a positive change of absorbance). The curves show a broad absorbance peak that is caused by localized surface plasmons or particle plasmons. These plasmons represent dipolar electron oscillations within the gold-nano-clusters which are excited by the electrical field of the incident light. At a certain frequency the oscillations are resonant giving a maximum absorbance. The plasmon frequency $\omega$ in the bulk metal is expressed by the formula 


$$
\omega=\sqrt{\frac{n e^{2}}{\varepsilon_{0} m_{e}}}
$$

where $n$ is the electron density, $e$ the electron charge, $\varepsilon_{o}$ the vacuum permittivity, and $m_{e}$ the electron mass [10]. When the metal particles are surrounded by another material, the $\omega$ is determined by the permittivity of the surrounding material instead of the vacuum permittivity. In our case the permittivity of the surrounding material (metal oxide) is changed at exposure to a reducing or oxidizing gas.

The observed absorbance peak in the red region explains the green-blue colour of the sample qualitatively. The position of the absorbance peak depends on the temperature of the sample. A shift towards higher wavelengths is observed at increasing temperature. The height of the peak depends on the size and amount of gold particles.

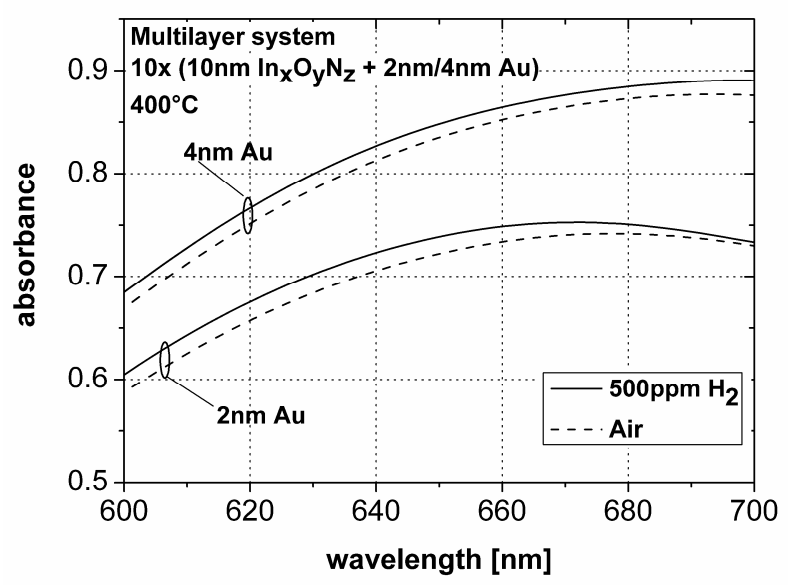

Figure 8. Absorbance of the multilayer system measured at an operating temperature of $400{ }^{\circ} \mathrm{C}$ in dry air and under exposure to $500 \mathrm{ppm} \mathrm{H}_{2}$ in dry synthetic air for a deposited gold thickness of $2 \mathrm{~nm}$ and $4 \mathrm{~nm}$.

The resonance peak in air appears at a wavelength of about $677 \mathrm{~nm}\left(400{ }^{\circ} \mathrm{C}, 2 \mathrm{~nm}\right.$ gold). Exposure to a reducing or oxidizing gas causes a spectral shift of the plasmon peak resulting in the positive or negative change of absorbance at a certain wavelength. In Fig.8 we show this very behaviour for the exposure to $500 \mathrm{ppm}$ of hydrogen (reducing gas). The absorbance is slightly increased in the observed spectrum and blue shifted about $6 \mathrm{~nm}$ to a resonance wavelength of $671 \mathrm{~nm}$. Other investigations showed a red shift during exposure to oxidizing gases [9]. The gas sensing effect, i.e., the gas dependent change of absorbance appears only at elevated temperatures.

The optimal operating wavelengths for gas detection with the presented composite layer system are those where the highest absorbance change can be observed.

\section{CONCLUSIONS AND OUTLOOK}

In this work we have demonstrated that the change of optical absorption of an $\mathrm{Au} / \mathrm{In}_{\mathrm{x}} \mathrm{O}_{y} \mathrm{~N}_{z}$ multilayer system with nano-scaled gold-clusters can be used to measure concentrations of reducing or oxidizing gases in dry air. The sensing effect can be used in a very easy manner utilizing a red LED as the light source and a photoresistor as the light detector. Spectral analysis showed a broad absorption peak which can be attributed to electron oscillations within the gold-clusters. The gold-particles are therefore a crucial component of the entire gas sensing system. The resonance peak is shifted during gas exposure resulting in the described change of absorbance by the multilayer system. The nano-gold-clusters used in our experiments up to now have been fabricated by sputter-deposition of ultrathin gold films. The clusters arise through coagulation during the annealing process at $600^{\circ} \mathrm{C}$ and the size depends on the film thickness. Alternatively, we have started to investigate a new deposition method which provides regular arranged gold-nano-clusters that can possibly enlarge the optical gas sensing effect (K. Piglmayer).

\section{ACKNOWLEDGEMENTS}

The authors would like to thank U. Gernert from the Berlin University of Technology, Center for Electron Microscopy, for preparing very valuable SEM micrographs (one example is shown in Fig.2).

\section{REFERENCES}

1. M. Ando, C. Swart, E. Pringsheim, V.M. Mirsky, O.S. Wolfbeis, Sensors and Actuators B 108 (2005) 528-534.

2. M. Ando, R. Chabicovsky, M. Haruta, Sensors and Actuators B 76 (2001) 13-17.

3. M. Ando, H. Steffes, R. Chabicovsky, M. Haruta, G. Stangl, IEEE Sensors Journal 04 (2) (2004) 232236.

4. M. Post, C. Cantalini, A. Martucci, D. Buso, M. Guglielmi, Technical Digest of Eurosensors XVIII, Rome, 12-15 Sept. 2004, 796-797.

5. C.F. Bohren, D.R. Huffmann, Absorption and scattering of light by small particles, John Wiley \& Sons, New York, USA, 1983.

6. U. Kreibig, M. Vollmer, Optical properties of metal clusters, Springer, Berlin, Germany, 1995.

7. H. Steffes, Ph.D. thesis (in German), Berlin University of Technology, Berlin, Germany, 2002.

8. H. Steffes, A. Schleunitz, U. Gernert, R. Chabicovsky, E. Obermeier, Microelectronic Engineering 83 (2006) 1197-1200.

9. A. Schleunitz, Diploma thesis (in German), Berlin University of Technology, Berlin, Germany, 2005.

10. H.P. Myers, Introductory Solid State Physics, London, U.K., Taylor \& Francis, 1990, pp. 153-158. 